\title{
The Application and Development Research of Artificial Intelligence Education in Wisdom Education Era
}

\author{
Ming Liu \\ Zhengzhou University of Industry Technology, China
}

Keywords: wisdom education; artificial intelligence; intellectual education; application

\begin{abstract}
With the development of computer technology and information technology, the application of artificial intelligence in education of technology is gradually thorough, becoming a trend in the development of computer teaching. Based on the intellectually auxiliary teaching according to the concept of education, this paper introduces the concept of wisdom education, and the content of artificial intelligence education. This paper introduces the concept, present situation and the existing problems of wisdom education teaching, expounds the relationship between artificial intelligence and wisdom education teaching system and the application of artificial intelligence in wisdom education, finally summarizes the intelligent computer system, and discusses the developing direction of wisdom education for the future of intelligent computer assisted instruction system.
\end{abstract}

\section{Introduction}

In many areas of computer science, artificial intelligence (AI) is a challenging and creative area. With the birth and development of artificial intelligence, people began to use computers for teaching. At the same time, since the 1970s, expert systems with teaching capabilities have been developed. The achievements of artificial intelligence technology and expert systems prompted people to introduce problem-solving and knowledge representation technologies into computer-aided instruction (CAI). This is Intelligent Computer Aided Instruction (ICAI). In recent decades, with the maturation of artificial intelligence technology, some of its research results have been applied to the field of teaching one after another, advancing the process of education development reform and teaching modernization [1]. The importance of artificial intelligence in the teaching system has also formed a consensus. Based on the concept of both wisdom education and computer-assisted teaching, this article introduces the concept of smart education, the scientific category and research content of artificial intelligence, and the characteristics of artificial intelligence. The concept, status quo, and some problems in the artificial intelligence teaching aided by wisdom education are introduced [1]. The relationship between artificial intelligence and wisdom education system and the application of artificial intelligence in computer aided teaching are described. Finally, the intelligent computer system is summarized, and the future development direction of intelligent education aided artificial intelligence teaching system is discussed.

\section{Wisdom education}

Wisdom education means education informatization refers to the process of comprehensively and in-depth use of modern information technology in education (education, education, education and scientific research) to promote education reform and development. Its technical characteristics are digital, networked, intelligent, and multimedia [1]. The basic features are openness, sharing, interaction, and collaboration. Education informatization is used to promote education modernization and information technology is used to change the traditional model.

The development of education informatization has brought about major changes in the forms of education and learning methods and promoted educational reform [1]. The traditional education ideas, concepts, models, contents and methods have had a tremendous impact.

Education informatization is an important part of national informatization. It is of profound significance for transforming education ideas and concepts, deepening education reform, improving 
education quality and efficiency, and cultivating innovative talents. It is an inevitable choice for achieving education leapfrog development.

\section{The main features of "artificial intelligence + education"}

The academic community generally believes that "Internet +" has features such as cross-border integration, innovation driven, remodeling of structure, respect for human nature, openness to ecology, and connectivity. The essence of "Internet + Education" is to uphold the concept of open education and to meet the new needs of education in the era of knowledge-based economy [2]. The value orientation is to promote the reform of the traditional school education system; Qin Hong and W.S. Zhang propose that "Internet + education" has a cross-border connection. , Innovation-driven, Optimized Relationships, Expanded Openness, and More Ecological Features: Z.Y. Li pointed out that from the perspective of teacher development, "Internet + Education" has six characteristics: high-density interoperability, high-efficiency generation, and large Scale-related, big data perception, familiarity with new things, and in differentness in new areas: X.M. Xiang pointed out at the "Forum of Artificial Intelligence and Future Education" forum that education in the smart age is a kind of "humanity is king" education. Something specific to human nature, such as virtue and emotion, deserves great attention.

\section{The role of "artificial intelligence + education".}

As early as 2005, UNESCO-APEID divided the development stage of education informatization (technical application in education) into four stages of emergence, application, integration, and innovation. According to this standard, on the basis of "Internet+education" promoting education informatization, "artificial intelligence+education" is at the stage of integration and innovation in the development of education informatization [2].

Specifically, "artificial intelligence + education" can improve teaching efficiency and effectiveness, provide better learning and intelligence for students, and provide teachers with better teaching services: From the knowledge level, "artificial intelligence + education" can promote knowledge generation, Disseminate, update, manage, and solve the problem of aging knowledge. From the perspective of learners, "artificial intelligence + education" can automatically perceive students' learning situations and make active adjustments so that learners can change from knowledge consumers to knowledge creators [2]. Cultivate students' innovative qualities; From the perspective of educators, it promotes teachers to re-think the role of educators, from the role of the teacher to the coach, and to make teaching activities mainly based on student experience and dynamic interaction. At the same time, teachers are liberated from cumbersome, trivial and repetitive tasks. In the future, tasks such as marking jobs and marking papers can be assisted by artificial intelligence.

More importantly, "Artificial Intelligence + Education" can redesign and present a new learning space and environment, changing the traditional teacher-student interaction and learning evaluation methods. With the help of technologies such as the Internet of Things, cloud computing, big data, VR/AR, and other technologies, the two benevolent interactions of "deep learning" are being continuously promoted.

\section{Four application forms of "artificial intelligence + education"}

At the macro-environmental construction level, it is pointed out that "a new education system should be established and a learner-centered education environment should be established." The micro-application form should include "building an intelligent campus, developing a three-dimensional integrated teaching field, and an online learning education platform based on big data intelligence. Develop intelligent education assistants." We believe that smart campuses, three-dimensional integrated teaching grounds, online learning education platforms based on big data intelligence, and intelligent education assistants are four forms of application of "artificial intelligence + education." 


\subsection{Intelligent Campus}

The smart campus is the further development of the digital campus, and it is also the material basis for building a smart campus. The smart campus is a campus-based, high-efficiency, comfortable, safe, convenient and environment-friendly campus environment that combines construction equipment, network communications, information appliances and equipment automation, system architecture, and service management [3]. The smart campus is based on the digitalization of resources and the networking of information flow. It is based on the application of electronic school affairs and application integration, and uses artificial intelligence technologies such as data warehouse and data mining technologies as means to achieve student learning, teacher teaching, and managerial decision-making. Intelligent and scientific, this is the typical application form of artificial intelligence + education. The smart campus aims to advance the modernization of education and teaching, informatization of scientific research activities, sharing of resources, management of science, and intelligent decision-making, so as to establish a digital, humane and intelligent campus community service system.

\subsection{Three-dimensional integrated teaching field}

The three-dimensional integrated teaching field is a place where the online and offline integrated teaching assistant teachers support individual learning of students, such as smart classrooms, digital laboratories, and comprehensive innovation laboratories. It is an important application of "artificial intelligence + education". form. The three-dimensional comprehensive teaching field is based on the discipline and integration of curriculum as a curriculum system [3]. It integrates diversified resources, diversified courses, and three-dimensional learning support to support students' initiative and individualized learning. It assists teacher teaching through artificial intelligence technology, and can design corresponding courses and teaching activities according to the characteristics of different students and provide students with intelligent learning services.

\subsection{An online learning education platform based on big data intelligence}

The online learning education platform based on big data intelligence is the mainstream application form of artificial intelligence + education. In the new-generation Internet environment based on cloud computing, the informatization of the whole process of education has produced a huge amount of educational data. Its massive and diverse sources come from real educational scenes and have enormous educational value. With the rise of big data and the development of data-intensive science, learning analytics and educational data mining have become the specific application of big data in the field of education [4]. An online learning education platform based on big data intelligence, incorporating learning analysis and educational data mining, capable of measuring and collecting learners and their learning environment data using statistics, machine learning, learning analysis and data mining techniques to analyze teaching and learning processes Generated data, understand and optimize learning and learning situations [4]. The online learning education platform based on big data intelligence provides learners with personalized adaptive learning services through the mining and intelligent analysis of educational data, intelligent assessment of real-time tracking and feedback, learning analysis and learner digital portraits. In short, based on the big data intelligence online learning and education platform, based on the "learner-centered" education concept, teaching big data to drive teaching is the "smart" embodiment of education big data.

\subsection{Intelligent education assistant}

Smart education assistants can assist teachers' teaching, student learning, and managerial management through lightweight educational applications. They provide users with convenient and intelligent education services. The core driver is artificial intelligence. At present, smart education assistants have intelligent tutors, education robots, and learning partners that assist in individualized teaching and learning. In addition, educational intelligence agents are also a form of technology for intelligent education assistants [3]. At present, smart education assistants have been favored by many educational users because of their convenience, but their level of "intelligence" in educational 
applications has yet to be improved. This is a promising application form of "artificial intelligence + education".

\section{Smart education assists in the development trend of "artificial intelligence + education"}

The establishment of a learner-centered education environment, the provision of accurate push education services, and the realization of daily education and customization of lifelong education require the full cooperation of schools, enterprises, and governments. The school provides excellent learning resources, advanced teaching theory, first-line learning data and other resources for the realization of "artificial intelligence + education", providing the correct educational theory guidance for the realization of "artificial intelligence + education"; at the same time, it is also "artificial intelligence" [4]. The "Education" important practice site is a major user of "artificial intelligence + education". Enterprises rely on advanced artificial intelligence technology to make efforts in the education industry, provide diversified personalized education products and services to the society, open the door to school education, and promote education to gradually face the society and the market. The government is the vane of "artificial intelligence + education" development. It formulates guiding policies and standards for the sustainable development of "artificial intelligence + education" and provides scientific guidance and services for companies to develop "artificial intelligence + education” products.

\subsection{Launch basic education artificial intelligence popularization activities}

Basic education is providing a science environment for artificial intelligence + education. Primary and secondary school students are the future of the country's development. It is particularly important that they popularize the science knowledge on artificial intelligence [5]. In the primary and secondary schools, artificial intelligence-related courses such as information technology courses and extended or research-based learning courses may be offered. These courses can fully integrate artificial intelligence technology and enhance primary and middle school students' understanding of artificial intelligence. At the same time, primary and secondary schools must also actively carry out relevant educational innovation activities, such as student education, STEAM education, and education robots, and encourage students to personally participate in learning and activities related to artificial intelligence.

\subsection{Construct artificial intelligence in higher education and training framework}

Higher education provides a solid academic foundation and talent base for "artificial intelligence + education". Colleges and universities are the main practice field for artificial intelligence + education. They should continue to improve the layout of artificial intelligence disciplines, set up artificial intelligence related disciplines, and systematically construct artificial intelligence related discipline courses [5]. Through the deep research of artificial intelligence theories, the promotion of artificial intelligence education practice will continue.

\subsection{Create artificial intelligence high-end talent team}

High-end talents are the leaders of artificial intelligence, and the artificial intelligence high-end talent team is a strong reserve force to promote the development of "artificial intelligence + education". To create high-level artificial intelligence innovation talents and teams for "artificial intelligence + education", it is necessary to adhere to the combination of training and introduction [5]. On the one hand, it is necessary to adhere to the three-dimensional talent cultivation model in which artificial intelligence leads the training of talents, artificial intelligence professionals and technical personnel, and artificial intelligence complex personnel training, and completely break the single, generalized high-end personnel training barriers. On the other hand, it is necessary to vigorously introduce various types of high-end artificial intelligence talents to attract top international scientists and high-level innovation teams through major R\&D tasks and base platform construction. Implement special policies for high-end talents to increase the talent introduction rate. 


\subsection{Strengthen artificial intelligence labor training}

Artificial intelligence is bringing about a new round of industrial changes. It urgently requires a new batch of laborers that can adapt to new employment structures and employment methods. These new types of laborers have certain artificial intelligence skills and are capable of meeting new occupations brought by artificial intelligence and meeting new types of needs [6]. Artificial intelligence labor force training needs schools, society, and enterprises to cooperate in many aspects. Institutions of higher learning, vocational schools, social training institutions, etc. shall actively carry out artificial intelligence skills training to upgrade the professional skills of the artificial intelligence workforce; society shall improve the construction of lifelong learning and employment training systems, and continue to bring high skills to the development of artificial intelligence [6]. Jobs provide high-quality workforce; enterprises must continuously strengthen the reemployment training and guidance of employees, and provide opportunities for workers to work on simple and repetitive tasks and those who are unemployed due to artificial intelligence.

\subsection{Cultivate major scientific and technological innovation bases}

The scientific and technological innovation base can provide theoretical basis and technical support for artificial intelligence + education. The cultivation of science and technology innovation bases can train and attract artificial intelligence high-end talents, promote the synergy between high-end talents, and promote the continuous development of artificial intelligence. In addition, the science and technology innovation base can serve as an artificial intelligence science popularization infrastructure and open to the public some of the facilities such as $\mathrm{R} \& \mathrm{D}$, production and other facilities [6]. At the same time, the artificial intelligence science and technology innovation base will be linked with national key laboratories related to artificial intelligence, national engineering laboratories, national engineering centers, etc., to combine strengths and strengths, complement each other's advantages, and jointly promote the research of the new generation of artificial intelligence frontier areas.

\section{Summary}

Computer-aided teaching and computer management teaching aim at optimizing education and teaching process. It is hailed as the fourth revolution in education history. It is an important content and means of modern educational technology and a breakthrough point for the current education revolution. Computer-aided teaching is not only an important field of computer application, but also an important technology for teaching, knowledge processing and knowledge transformation. Computer-aided teaching is not only an important content of knowledge engineering, but also a product of computer technology and information technology. Computer-aided teaching is at the intersection of knowledge economy, knowledge engineering, knowledge innovation, science and education, country rejuvenation, science and technology, and education. With the development of artificial intelligence technology, the effectiveness of computer-aided teaching will become more apparent. In the current environment of educational reform, more educators should pay attention to the construction and development of ICAI and play a greater role in promoting the development of the ICAI system.

\section{References}

[1] X.T. Zhang, Basic Principles and Production Techniques of Multimedia CAI Courseware, Beijing: Beijing University of Aeronautics and Astronautics Press, 2000, vol. 2, pp. 13-15.

[2] W.S. Wang, Principles and Applications of Artificial Intelligence, Beijing: Publishing House of Electronics Industry, 2004, vol. 3, pp. 34-37.

[3] H.Y. Lu, Artificial Intelligence, Beijing: Science Press, 2003, vol. 12, pp. 11-13.

[4] W P.F. Sun, Computer-aided teaching, Hohhot: Inner Mongolia University Press, 2010, vol. 9, pp. 
$16-18$.

[5] J.H. Wang, Practical Tutorial for Computer Aided Instruction, Higher Education Press, 2013, pp. 43-47.

[6] Z.T. Zhu, Information Technology Education Outlook, Shanghai East China Normal University Press, 2011, vol. 8, pp. 18-21. 